\title{
Subject Cataloging of Personality Tests
}

\section{Robert P. Jordan}

\begin{abstract}
Many large universities maintain personality test collections. Often, a librarian is in charge of both the tests' acquisition and their organization. If a collection contains many personality tests and if the clientele utilizing these tests comes from various academic backgrounds, the librarian must cope with requests to find instruments by variable tested. The development and use of an arrangement of subject subheadings as retrieval points for personality tests becomes essential.
\end{abstract}

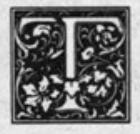

he need for subject headings for personality tests increases as the collection grows. Psychologists or counselors who are familiar with the tests located in one or two file drawers do not need an extensive number of retrieval points for their collections. But when hundreds of tests comprise such a collection, the person in charge, often a librarian who is not a subject specialist utilizing the collection on a regular basis, needs some form of subject cataloging.

The librarian may physically arrange the instruments by the variable of subject area tested instead of alphabetically by title or author. For example, the librarian could file mathematics tests after intelligence tests and before personality tests. The librarian may then develop a subarrangement by title, author, or age group. The grouping by subject is actually a form of classification. Again, for a handful of tests, such an arrangement may be sufficient. But as library personnel add more tests to the collection or as the variables being tested become narrower in scope, the librarian must develop a system of assigning subheadings, which would ordinarily be designated by broad categories such as "Mathematics," "Reading," or "Personality."

\section{REVIEW OF RELATED RESEARCH}

Several other librarians and one subject specialist have attempted to address the problem of developing some system whereby tests can be retrieved by subject. In Organizing and Servicing a Collection of Standardized Tests, Robert M. Simmons wrote that "heavily used collections will be a constant plague to the responsible librarian unless a sophisticated retrieval system is developed."1 $\mathrm{He}$ called both the Library of Congress subject headings and the subject index in the Mental Measurements Yearbook series inadequate. ${ }^{2,3}$ Yet Simmons does not describe a means by which such systems can be expanded to facilitate better retrieval of tests, especially personality tests, by subject.

In 1985, the Ad Hoc Subcommittee on Test Collections of the Education and Behavioral Sciences Section of the Association of College and Research Libraries published, through ACRL, the Guide for the Development and Management of Test Collections with Special Emphasis on Academic Settings. ${ }^{4}$ It contains a chapter on bibliographic control and access. The au-

Robert P. Jordan is the Test Resources Librarian for Iowa Testing Programs at the University of Iowa, Iowa City, Iowa 52242. 
thors suggest "an expansion or modification of the Buros' Mental Measurements Yearbook system" when that system's categories become unworkable. ${ }^{5}$ The subcommittee indicated that the Thesaurus of ERIC Descriptors might be a possible "basis of a subject authority file." ${ }^{6}$ The Thesaurus of Psychological Index Terms might, however, be more appropriate for an expansion of Buros' category of "Personality" if librarians were to consult an already existing list of indexing terms. ${ }^{\text {? }}$

In "Selected Test Collections in the United States: A Survey of Organization," Nancy $O^{\prime}$ Brien and David Ginn noted that among the test collections surveyed, almost "all of these collections utilized a system of classification that incorporated aspects of the Buros system with expanded or modified classifications." James V. Mitchell, Jr., in his article "A Potent Triumvirate: Librarian, Buros Institute, and Test User," instructed his readers in the use of the Score Index and the Classified Subject Index. ${ }^{9,10}$ He suggested these indexes as two possible avenues for librarians to retrieve tests by subject. When searching for a particular personality test variable, the Classified Subject Index is useless because all personality tests are together subarranged only by title. ${ }^{11}$ However, the Score Index has indeed been a boon to test librarians even though it does not contain information on all tests held at the Buros Institute of Mental Measurements or in a local test library. The Score Index's limitations will be discussed more fully below.

\section{USE OF COMPUTER DATABASES}

In his monograph, Simmons wrote that a computerized retrieval system would be needed to index a test collection adequately. He stated that "equipment to perform [that] type of search. . . will not be available at many institutions." ${ }^{12}$ But with the advent of personal computers and software programs for word processing, that statement is no longer true. In any event, a system of subject subheadings must be introduced to a local collection of personality tests whether the list is locally generated or adapted from an outside source, such as a database.
According to Susan Klingberg, Bibliographic and Reference Services installed two online databases that deal with tests. ${ }^{13}$ One database, the Mental Measurements Yearbook (MMYD), has a familiar coverage. The other database is based on Educational Testing Service's Test Collection (ETSF). MMYD can be searched using the score paragraphs from which Mitchell and the Buros Institute staff derived the Score Index for the print versions of the ninth and tenth Yearbooks. ${ }^{14}$ Thus, the user of MMYD has essentially the same tool. MMYD, of course, gives the searcher more current information in one source.

\section{A system of subject headings must be introduced to a local collection of personality tests.}

ETSF utilized the Thesaurus of ERIC Descriptors for its subject headings. Klingberg shows that successful search strategies often entail several steps. ${ }^{15}$ Because the purpose of an online search is to find all pertinent tests on a patron's topic, such searches would be worth the cost. But for a patron who wants to know what personality tests are available locally on depression, anxiety, self-esteem, and so on, searching outside databases is inefficient. Searching a subject catalog of the local test collection is more efficient than searching large databases and then cross-checking against local author or title files. If patrons find nothing appropriate, they can either reformulate their requests, knowing the extent of the local collection, or search outside databases.

\section{REQUISITE CONDITIONS TO DEVELOP LOCAL SUBHEADINGS}

Three conditions should trigger the development and utilization of a list of subject subheadings for a local collection of personality tests. First, bibliographic control is essential. Simmons outlined several options including a simpleauthor/title card file and a computer listing. ${ }^{16}$

Second, collections need subject subheadings. Because patrons often are not sure about which specific tests they 
T0003

\section{Reynolds adolescent depression scale / by William \\ M. Reynolds.-Odessa, Florida: Psycho- logical Assessment Resources, c1986-87.}

Figure 1. Title main entry for the RADS

want, the librarian must conduct a reference interview. ${ }^{17}$ In some cases, patrons have initial expectations of finding instruments to measure exactly what they want. If such instruments are not available, the patrons may have to adjust their expectations to what is available locally.

\section{Searching a subject catalog of the local test collection is more efficient than searching large databases and then cross-checking against local author or title files.}

For instance, at the library of the Iowa Testing Programs (ITP library), a patron wanted to find an instrument to measure attitudes toward the importance of vocational education for the educable mentally handicapped. Such an instrument may exist somewhere, but not in the ITP library. The librarian did find an instrument that claimed to measure parental attitudes toward the mentally handicapped in several settings including school. ${ }^{18}$ It was a start. The test librarian needed a subject grouping of tests with stable vocabulary control to locate the material.

The third condition is that the existing subject groupings are not adequate for a particular library and its mission. Examples of existing bibliographies are Tests in Print III, Tests, third edition, ETS Test
Collection Catalog, ETS Complete List of Bibliographies, and The Mental Measurements Yearbooks with Score Index. ${ }^{19-23}$

In 1975, the staff at the ITP library organized and cataloged several hundred outof-print tests into the archival historical test file. The staff decided to use subject headings from Buros' Tests in Print II (TIP II).$^{24}$ In spite of some idiosyncrasies, Buros' array of headings worked well with added cross-referencing. In a 1977 visit, Buros was surprised and pleased to discover the library's adaptation of his system. A separate current test file contains in-print test specimen sets and kits maintained for study by faculty and graduate students in the College of Education at the University of Iowa. Fifteen years later, the system has been expanded only slightly. A librarian catalogs new tests with a minimum description. Because author, editor, and publisher roles blur, main entries are under title, with added entries for subjects and other responsible parties. Staff members file cards into a separate catalog (see figure 1; further samples and discussion are available from the author.)

The T0 number is the test's accession number. The ITP library's staff does not assign classification numbers to tests. ITP personnel retrieve the tests from a locked file cabinet after patrons identify them in the catalog. This practice follows that of the Standards for Educational and Psychological Testing, prepared by the Committee to 
Develop Standards for Educational and Psychological Testing. ${ }^{25}$

In 1980, the main part of the University of Iowa's College of Education moved into its current building attached to the one housing the Iowa Testing Programs. With various component departments of the college came their needs in the testing field. Instead of supporting only the Iowa Testing Programs, the ITP library (since renamed the Paul Blommers Measurement Resources Laboratory) became a de facto resource for the divisions of Counselor Education and of Psychological and Quantitative Foundations. Over the years, growing numbers of faculty, staff, and students from the colleges of nursing, business administration, and medicine have used the ITP library. The number of specimen sets and kits of tests utilized by these patrons has doubled the size of the current test file since 1980. The ITP library staff retired older editions of tests to the historical test file as new editions appeared. Added to that were the 800 plus instruments in theongoing Tests in Microfiche series, most of which do not assess academic achievement. ${ }^{26}$

By 1982 , the library staff realized that an expansion of subheadings for personality tests was needed. At that time, personality tests weresubdivided into "Projective" and "Nonprojective," both in TIP II and the ITP library. Because of the growing numbers of patrons with diverse interests in measurement, the staff began to shift test acquisitions not only from the cognitive domain, but also to those measuring variables in the affective domain. Because most of these affective domain variables were already considered "Personality" measures in TIP II and later in Tests in Print III (TIP III), the staff decided to retain that term as the major subject heading, with "Projective" as a subheading. Because the overwhelming majority of personality tests in the ITP library were "Nonprojective," the staff decided to discontinue the use of that term. Staff consulted several sources on personality testing to discover possible subheadings. ${ }^{27}$

\section{TEST VARIABLES AS SUBJECT SUBHEADINGS}

Asystem of personality test subheadings still had to be more specific than what the measurement authorities had done. For more than fifteen years, the experience of the ITP library staff has been that most patrons come in looking for a test that assesses a particular variable or set of variables, whether in the cognitive or affective domains. Technique of assessment was a secondary consideration.

\section{A cataloger should catalog a book or other medium of several specific top- ics into the narrowest subject heading under which all topics could fit.}

The ITP library staff decided that the hundreds of tests in the current test file with the subject heading "PersonalityNonprojective" should be canvassed for the variables tested. The staff searched the tests' manuals as well as the various descriptive bibliographies mentioned above to see what authors and other subject specialists had indicated the variables of those tests were. In the case of the Minnesota Multiphasic Personality Inventory (MMPI), the 16PF Questionnaire, and other multitrait instruments, the staff decided to use only "Personality" as the subject heading. This decision was in keeping with the basic tenet in librarianship that a cataloger should catalog a book or other medium of several specific topics into the narrowest subject heading under which all topics could fit. ${ }^{28}$ Otherwise, a cataloger might assign up to sixteen subheadings to the 16PF Questionnaire. But in the case of a test where only one, two, or three variables are tested, the cataloger would assign subject subheadings for each distinct variable. (A copy of these subheadings is available from the author.)

When the staff completed the canvas of tests, the number of variables tested for could easily be handled. Some argument could be made that terms such as "Hostility" and "Aggression" are the same or could be combined. And there are other groupings or terms that might make behavioral scientists cringe because of choice of words or their own biases in training or thinking. Three sources of authority, however, supported the inclusion of these sub- 
headings. TIP II and TIP III as well as the Mental Measurements Yearbooks series placed many diverse tests into "Personality." For example, when the staff decided three years ago to add the subheading "Eating Disorders" to the list at the ITP library, they did it knowing that tests such as the Eating Disorder Inventory were still considered personality tests in The Ninth Mental Measurements Yearbook. Physicians, psychologists, and nutritionists could argue that bulimia or anorexia nervosa might have genetic or hormonal bases. But the tests are designed only to measure occurrences of or susceptibilities to certain eating behavior disorders. Therefore, if there existed any doubt as to whether a test were actually a personality test, the staff checked its status in appropriate references. ${ }^{29}$

\section{FUTURE OPTIONS}

Perhaps in later editions of the Mental Measurements Yearbook, the editors will decide to arrange personality tests in its Classified Subject Index using subheadings. From a past study by Ginn and
$\mathrm{O}^{\prime}$ Brien, test libraries may adapt such a change in the Mental Measurements Yearbook arrangement. ${ }^{30}$ Another option might be available in the fifth volume of The ETS Test Collection Catalog. That volume is scheduled to be published in 1991 and should contain information on personality tests held in ETSF. Its index may provide an adaptable system of subheadings. Until either of these options is developed, however, the list of personality subheadings developed at the ITP library exists and works.

\section{CONCLUSIONS}

This study explains the rationale behind a list of subject subheadings for personality tests. The list is as much practical as it is theoretical. Though subject specialists were consulted at the list's inception, the demands of patrons and the ITP library staff's experience forged the current product. As test authors publish new personality instruments that may be added to the ITP library's collection, the staff will, no doubt, be required to make additions, consolidations, and deletions.

\section{REFERENCES AND NOTES}

1. Robert M. Simmons, Organizing and Servicing a Collection of Standardized Tests: AManual for Librarians, Alexandria, Va.: ERIC Document Reproduction Service, ED 180 434, 1979); microfiche, p.7.

2. Ibid., p.7.

3. Oscar K. Buros, ed., Mental Measurements Yearbook, 1st-8th eds. (Highland Park, N.J.: Gryphon, 1938-1978).

4. American Library Association, Association of College and Research Libraries, Education and Behavioral Sciences Section Ad Hoc Subcommittee on Test Collections, Guide for the Development and Management of Test Collections with Special Emphasis on Academic Settings (Chicago:ACRL, 1985).

5. Ibid., p.12.

6. Thesaurus of ERIC Descriptors, 10th ed. (Phoenix, AZ: Oryx, 1984).

7. American Psychological Association, PsycINFO Department Retrieval Services Unit, Thesaurus of Psychological Index Terms, 5th ed. (Washington, D.C.: American Psychological Assn., 1988).

8. David Ginn and Nancy O'Brien, "Selected Test Collections in the United States: A Survey of Organization," Behavioral and Social Sciences Librarian 4:9-20 (Winter 198485/Spring 1985).

9. James V. Mitchell, Jr. "A Potent Triumvirate: Librarian, Buros Institute, and Test User." $R Q$ 26:328-34 (Spring 1987).

10. James V. Mitchell, Jr., ed. The Ninth Mental Measurements Yearbook, (Lincoln, NE: Buros Inst. of Mental Measurements, 1986); distributed by the Univ. of Nebraska Pr.

11. Jane Close Conoley and Jack J. Kramer, eds., The Tenth Mental Measurements Yearbook. (Lincoln, NE: Buros Inst. of Mental Measurements, 1989); distributed by the Univ. of Nebraska Pr. 
12. Simmons, Organizing and Servicing a Collection of Standardized Tests, p.11.

13. Susan Klingberg, "Online Access to Tests: The ETSF and MMYD Databases," Reference Services Review 12:15-19 (Winter 1984).

14. Mitchell, "A Potent Triumvirate," p.332.

15. Klingberg, "Online Access to Tests," p.16-17.

16. Simmons, Organizing and Servicing a Collection of Standardized Tests, p.7-12.

17. Robert S. Taylor, "Question-Negotiation and Information Seeking in Libraries," College E Research Libraries 29:178-194 (May 1968).

18. Harold D. Love, Parental Attitudes toward Mentally Retarded Children Scale, Tests in Microfiche no. 009428. (Princeton, N.J.: Educational Testing Service, 1967). Microfiche.

19. James V. Mitchell, Jr., ed. Tests in Print III: An Index to Tests, Test Reviews, and the Literature on Specific Test (Lincoln, NE.: Buros Inst. of Mental Measurements, 1983); distributed by the University of Nebraska Pr. This index does not group tests except insofar as the terminology of the scores, or variables, is similar. This terminology, much like a keyword index, is determined exactly by the test authors' choice of wording. These terms can sometimes be unwieldy. "Holistic and primary-trait scores for narration" and "identification of colors and shapes and copying shapes" are two such cumbersome variables as entered into the Score Index of the The Ninth Mental Measurements Yearbook (p.1971). In the latter example, most researchers would look under "shapes," "colors," or "copying" instead of "identification," but the test in question is indexed only under "identification." Another example of a score for a personality test is "incongruence between present and ideal sex-role behavior"(p.1972). Again, most researchers would look under "sex-role" for such instruments, not under "incongruence." This instrument is not indexed under "sex-role." Thus, a researcher might not find this particular instrument unless searching online with MMYD. Patrons should be able to locate all instruments in a test library, or a test bibliography in book format, on a topic as succinct as "sex-role."

20. Richard C. Sweetland and Daniel J. Keyser, eds., Tests: A Comprehensive Reference for Assessments in Psychology, Education, and Business, 3rd ed. (Austin, TX.: PRO-ED, 1991).

21. Educational Testing Service, Test Collection, The ETS Test Collection Catalog, 5 v. (Phoenix, AZ: Oryx, 1986-1991.)

22. Educational Testing Service, Test Collection, ETS Test Collection Complete Listing of Bibliographies (Princeton, N.J.: Educational Testing Service, [1989]).

23. Mitchell, "A Potent Triumvirate," p.329.

24. Oscar K. Buros, ed., Tests in Print II: An Index to Tests, Test Reviews, and the Literature on Specific Tests (Highland Park, N.J.: Gryphon, 1974).

25. Committee to Develop Standards for Educational and Psychological Testing, Standards for Educational and Psychological Testing (Washington, D.C.: American Psychological Assn., 1985).

26. Educational Testing Service, Test Collection, Tests in Microfiche (Princeton, N.J.: Educational Testing Service, 1975-1990).

27. The staff consulted several sources on personality testing to discover if subject specialists in psychology had done anything in the way of categorizing personality instruments. Anne Anastasi made distinctions among them by technique of assessment: self-report inventories; measuring interests, values, and attitudes; projective techniques, and "other" techniques. See Anne Anastasi, Psychological Testing. 5th ed. (New York: Macmillan, 1982), passim. Anastasi initially categorized by how the assessment was done, not by what variables were assessed. Cliff $\mathrm{W}$. Wing also divided tests of personality into techniques used. In this case, they were projective techniques, selfevaluating techniques, and observations of behavior. See Cliff W. Wing, Jr., "Measurement of Personality," in Handbook of Measurement and Assessment in Behavioral Sciences, ed. Dean K. Whitla (Reading, MA: Addison-Wesley, 1968), passim. Anastasi included this latter technique among her "other" techniques. But because Wing thought it important enough, the ITP library staff decided to use "Behavior Observation" along with "Projective" as the first two subheadings used with personality tests in the library. Lee J. Cronbach also divided personality tests into self-reports, observation instruments, performance tests, and assessment of personality dynamics. See Lee J. Cronbach, Essentials of Psychological Testing, 3rd ed. (New York: Harper \& Row, 1970), passim. However, within these divisions by technique, Cronbach categorized perceptions and reactions-in other words, the variables that can be tested. Two of Cronbach's 
variables, for example, were self-concept and attitude toward authority. Robert L. Thorndike and Elizabeth P. Hagen, in their measurement textbook's chapter on questionnaires and inventories for self-appraisal, outlined five aspects of personality: temperament, character, adjustment, interests, and attitudes. See Robert L. Thorndike and Elizabeth P. Hagen, Measurement and Evaluation in Psychology and Education, 4th ed. (New York: Wiley, 1977), passim. Thorndike and Hagen indicated that these aspects of personality could be evaluated by 1 ) what individuals say about themselves, 2) what others say about the individuals, or 3) how the individuals behave as recorded by observers.

28. Bohden S. Wynar and Arlene G. Taylor, Introduction to Cataloging and Classification, 7th ed. (Littleton, CO: Libraries Unlimited, 1985).

29. The third edition of the American Psychological Association's Thesaurus of Psychological Index Terms was published about the time the ITP library staff completed the expansion of the "Personality" subject heading. See Thesaurus of Psychological Index Terms, 3rd ed. (Washington, D.C.: American Psychological Assn., 1982), passim. Though this work was not used in the initial development of the ITP library's list of subheadings, the staff has consulted it and its later editions for appropriateness of new terms considered for addition to the list. In some cases, the staff has decided to use a more familiar term than the one indicated in the Thesaurus of Psychological Index Terms. An example is "Personality-Eating Disorders." According to the latest edition of the Thesaurus of Psychological Index Terms, the term to use is "Appetite Disorders." See American Psychological Association., Thesaurus of Psychological Index Terms 5th ed., p.16. Yet not one patron in the last fifteen years has come into the ITP library and inquired about tests using that phrase. Patrons use "Eating Disorders" when looking for such tests. Test and book authors use "Eating Disorders" to describe these syndromes. The Encyclopedia of Psychology has entries under both terms, but the one under "Eating Disorders" is much more extensive even though the scope of both entries is similar. See Raymond J. Corsini, ed., Encyclopedia of Psychology, 4 v. (New York: Wiley, 1984), passim. Therefore, the ITP library staff decided to retain that term in lieu of "Appetite Disorders." The Thesaurus of Psychological Index Terms, then, is only a guide when test variables are vaguely defined by the authors or defined with multiple cognates.

30. Ginn and O'Brien, "Selected Test Collections in the United States," p.14-15. 